\title{
Mechanical properties of silica, graphite and carbon fiber reinforced composites
}

\author{
Mustafa A. Rijab ${ }^{\# 1}$, Ekhlas I. Kader ${ }^{* 2}$, Ali A. Hamod ${ }^{* 3}$, Abdul Hameed I. Hameed ${ }^{* 4}$ \\ * Mechanical Depart., Technical Institute of Baqubah, Middle Technical University \\ Baqubah, Diyala Governorate, IRAQ \\ 1 mustafaalnajar677@yahoo.com \\ *Mechanical Depart., Engineering College, Diyala University \\ Baqubah, Diyala Governorate, IRAQ \\ 2 eng-ekhlas@yahoo.com, ${ }^{3}$ adwan@engineering.uodiyala.edu.iq
}

\begin{abstract}
The research aims to study the mechanical properties included impact strength and flexural strength of composite materials consists of epoxy resin with phenolic formaldehyde resin reinforced by graphite or silica particles or both, and reinforced with carbon fibers of a standard format $(-90,0,+90)$. The results obtained showed that the mechanical properties of epoxy- phenolic formaldehyde resins are enhanced after reinforced by silica, graphite and carbon fiber.
\end{abstract}

Keyword - Epoxy, phenol formaldehyde resin, particles reinforcement, carbon fibers, mechanical properties

\section{INTRODUCTION}

Composite materials in this regard represent nothing but a giant step in the ever-constant endeavor of optimization in materials. Strictly speaking, the idea of composite materials is not a new or recent one. Nature is full of examples wherein the idea of composite materials is used[1]. In the 20th century, modern composites were used in the 1930s when glass fibers reinforced resins. Boats and aircraft were built out of these glass composites, commonly called fiberglass . Since the 1970s, application of composites has widely increased due to development of new fibers such as carbon, boron, and aramids, and new composite systems with matrices made of metals and ceramics[2]. Phenol formaldehyde resins is a type of polymer is made from two main substances: phenol and formaldehyde. Phenol is a colorless solid compound, but when exposure to oxidation in the air its colored by pink Then brown. It has strong odor and penetrating. Phenol is widely used in the manufacture of materials for plastics, including drinking water bottles, as well as in the clothing industry. Phenol is used in the installation of nylon. It has medical uses, it is used in the manufacture of disinfectants, lotions, ointments, topical anesthetics and the pharmaceutical industry[3]. The water solution which contains a concentration of $40 \%$ formaldehyde is called formalin. this is used as a preservative for tissues and in embalming, with a boiling point of $21^{\circ} \mathrm{C}$, it is used in veterinary and in dentistry as well as in the production of chemicals and polymers and is often used in the manufacture of coatings and explosives [4].In general, phenolformaldehyde produced by two ways, for manufacture two types of polymers, namely Novolac and Resole [5]. Novolac is a type of polymers produced by mixing formaldehyde ( $37 \%$ water solution) with phenol by added an acidic helper (sulfuric, phosphoric or oxalic acid), and heated to the required degree and then equivalent the reaction mixture, and remove the water by distillation (in its final stages under discharge) to a temperature Estimated $160^{\circ} \mathrm{C}$. Resole is a type is produced by added basic helper with more formaldehyde relative to phenol. Initially, its consists (Oligomer) is called a resole and it is not needed to a hardener (HMTA) but it need just heat treatment $[3,6]$.

\section{EXPERIMENTAL PROCEDURE}

Material used: The material used in this work are: (1) Epoxy resin LEYCO-POX 103, (2) phenol formaldehyde (resole) resin, (3) graphite particles, (4) silica particles, and (4) carbon fibers.

Mixing process: The epoxy resin $(80 \%)$ was mixed with phenol formaldehyde resin with the ratio $(80: 20) \%$ as a matrix and the renforcing material was three types as shown in Table.1.

TABLE I. Composition of composite

\begin{tabular}{|l|c|c|c|}
\hline \multicolumn{2}{|c|}{ Sample No. } & \multicolumn{3}{c|}{ Reinforcement, \% } \\
\cline { 2 - 4 } & Carbon fibers (CF) & Silica (S) & Graphite (G) \\
\hline \begin{tabular}{l} 
ER3 $\begin{array}{l}(80 \% \text { epoxy }+20 \% \text { phenol } \\
\text { formaldehyde) }\end{array}$ \\
\hline ER3+S+CF
\end{tabular} & - & - & - \\
\hline ER3+G+CF & 20 & 20 & - \\
\hline ER3+S+G+CF & 20 & - & 20 \\
\hline
\end{tabular}


Samples preparation and Calculation of Mechanical properties: (1) Impact samples were fabricated according to the (ASTM-E23) standard suitable to Charby Impact Instrument (Fig.1).Notch depth is $(0.5 \mathrm{~mm})$ and notch base radius is $(0.25 \mathrm{~mm})$. (2) Flexural strength samples: were fabricated according to (ASTM-D790) standard as a rectangular shape $(10 \mathrm{~mm} \times 135 \mathrm{~mm})$. Flexural strength was measured by three point test by using universal hydraulic press (Leybold Harris No.36110) to calculate the maximum load exposed on middle of the Sample.

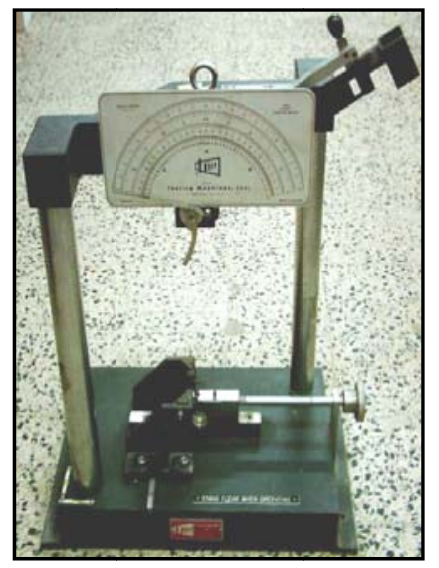

Fig.1 Impact test instrument

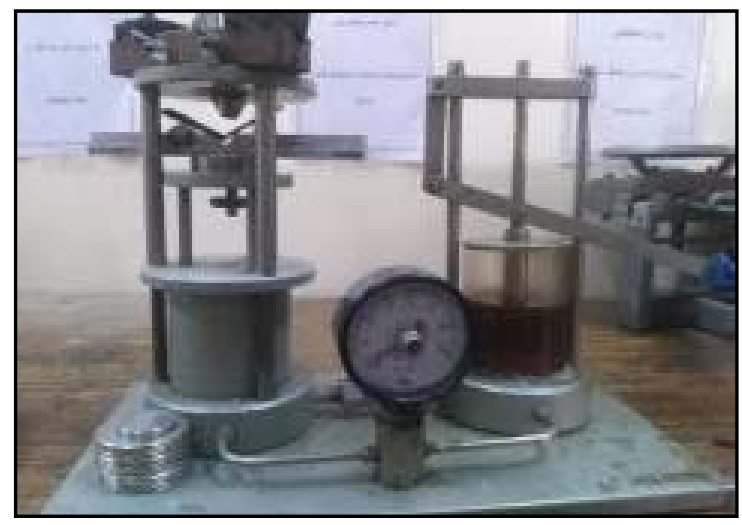

Fig.2. Flexural test instrument

\section{III.RESULTS AND DISCUSSION}

All paragraphs must be indented. All paragraphs must be justified, i.e. both left-justified and right-justified.

Fig.3 represents impact strength of composites. The impact test is one of the important dynamic mechanical tests in which the material undergoes a very rapid motor load. The impact test of the samples was carried out in a Charby method at room temperature, which is one of the three-point flexural test images. The impact strengthe of the Composite material $(\mathrm{Gc})$ and the impact breaking strength of the Composite material $(\mathrm{Kc})$ were calculated using the energy needed to obtain the fracture in the sample ( $\mathrm{Uc})$, which was measured by the probe and using the Eb curve flexural coefficient obtained from the flexural test, In the previous studies and the current study, the samples are divided into two parts, which suffer from fragile fracture at the point of impact of the sample with pendulum, while other samples have a fractional fracture, where the values of resistance to the impact decreases with the increase of fractional volume of the graphite and silica minutes, The minutes are weak in the scalability of the resistor The fracture of both graphite and silica was confirmed in this study. Therefore, the impact resistance values for the samples supported by graphite and carbon fiber are higher than the values their samples are supported by silica and carbon fiber.

This may be due to the nature of the samples supported by graphite and carbon fiber reinforced with high impact resistance and durability compared to silica-supported and carbon fiber-reinforced samples that have the characteristic Easy to break into small pieces. As for the effect of the particle size of the supporting particles on the impact resistance values of the samples, the impact resistance values decrease with the increase in the minute size of the minutes due to the difficulty of penetrating those large minutes inside the base material and into the fiber mesh interface, which reduces the wetability of the base material of the reinforcing materials. The contact area and then the weak bonding between the components of the overlapping material prepared as well as creating a lot of defects, which act as centers to focus the stresses and reduce the energy needed to break and 
thus reduce the values of resistance to impact. The severity of the impact fracture, as indicated by previous studies, [7-8] indicates a small increase in the increase of the fractional fraction of the reinforced particles by the composite material (graphite and silica). The increase in the fractional energy of the composite material prepared to withstand the reinforcement materials is part of the impact stress This material is based on the strength of the bonding between the reinforcing materials and the base material for the transfer of the fracture during the interface around the substrate.

For minutes in case of failure of minutes, in addition to the dependence of this relationship on the fraction of volume, shape, size and distribution system within the base material, then the last value of the durability of the impact break down the material slightly to increase the percentage of minutes that lead to weak mixing with the base material, And the increase of the interfaces between the base material and reinforcement materials will lead to increased defects and decrease in the amount of energy needed for the occurrence of fracture and this is what the researcher (BF Blumentrit) that the material is torn when there are cracks in the base material and at the boundary between the base material and materials The previous studies have indicated the effect of the minute size of the graphite on the strength of the fracture, where the fracture strength was found to decrease with the increase in the size of the graphite minutes.

This is due to the fact that the use of minutes in small sizes will facilitate the base material mixed with the minutes of the graphite penetration To the inside of the interwoven network within the fiber network and facilitate the process of wetting the base material for all surfaces of the materials of the reinforcement and thus will increase the demand and increase the strength of bonding between the reinforcing materials and the base material, which eventually lead to withstand impact stress with higher values and the contrary The work of the large minutes to create a lot of defects and gaps and aerobic space, which reduces the wetness as well as the creation of areas for the concentration of stresses, which helps to accelerate the growth of the fracture and thus to break the sample with a lower impact load, and also notes through the current study that the values of fracture strength of samples supported by graphite minutes Silica and carbon fiber are higher than their counterparts in graphite or silica particles, given the high durability of carbon fibers and impact tolerance.

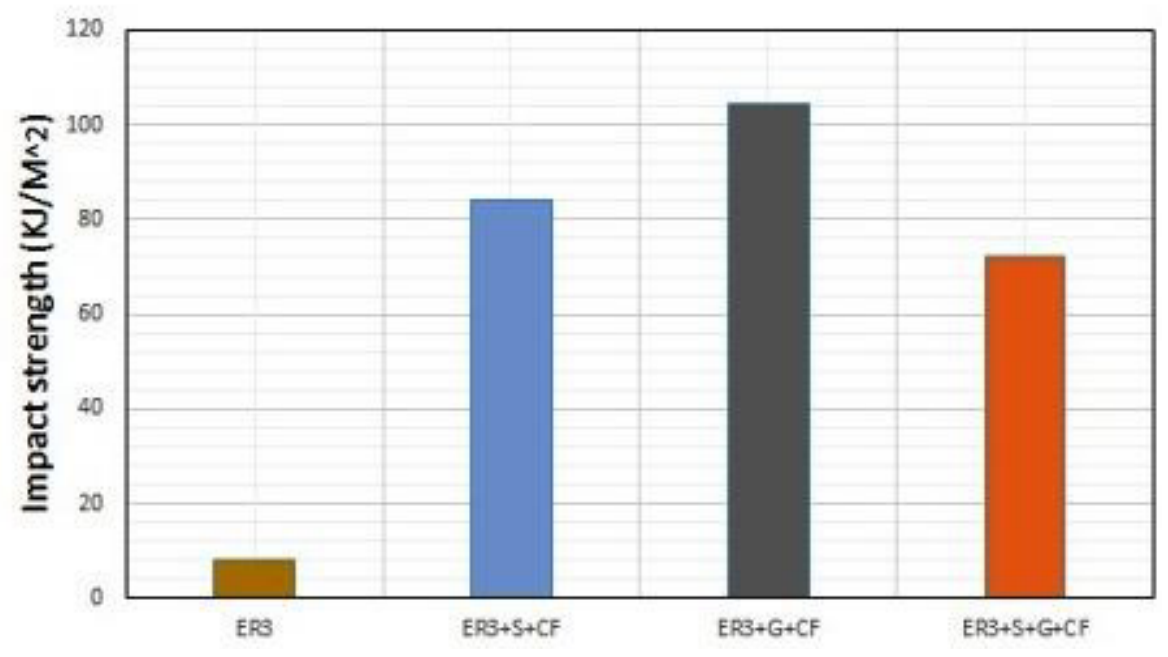

Fig.3. Impact strength of composites

Fig.4 represents the flexural strength of composites. The flexural strength test is a complex test because the sample is subjected to several stresses at the same time: the tensile stress at the outside of the sample, the pressure stress on the inner surface of the sample and the shear stress that occurs at its interface. The overlapping material fails under the influence of one of these three stresses Depending on the type of reinforcement material and the strength of the bond between them and the base material where it was found through previous studies that the values of flexural strength and the values of the shear stress increased when adding the minutes of graphite and silica to the base material armed with carbon fiber, The graphite and silica graphite are highly resistant to compressive stress and gypsum compared to carbon fiber, but increasing the fraction of the graphite and silica minutes reduces wetting within the base material, making it a concentration of stresses, thus increasing defects and cracks, thus weakening the bond between the base material And the reinforcement material and the sample fails completely.

The effect of the perpendicular size of the graphite and silica particles on the flexural strength values and the stress weight values showed that the use of minuscule minutes in small minute sizes $(75 \mu \mathrm{m}$ PS PS> $25 \mu \mathrm{m})$ and volumetric fracture of the graphite $(10 \%)$ resulted in increased flexural strength values, With the values of their counterparts supported by the graphite minutes and fractional size (10\%) with large minuscule sizes $(106 \mu \mathrm{m}$ PS PS $>90 \mu \mathrm{m})$. This is due to the fact that the use of small-size graphite minutes will facilitate the wetting of the 
base material of the reinforcement materials, The overlapping material is prepared and then $\mathrm{z}$ The higher the bond strength between them and ultimately increases their tolerance to external stresses. The lower flexural values and shear stress values are also observed with the increasing size of the graphite minutes because the use of large minutes reduces the wetting of the base material and increases the formation of air defects and spacing. Overlapping of external loads [9].

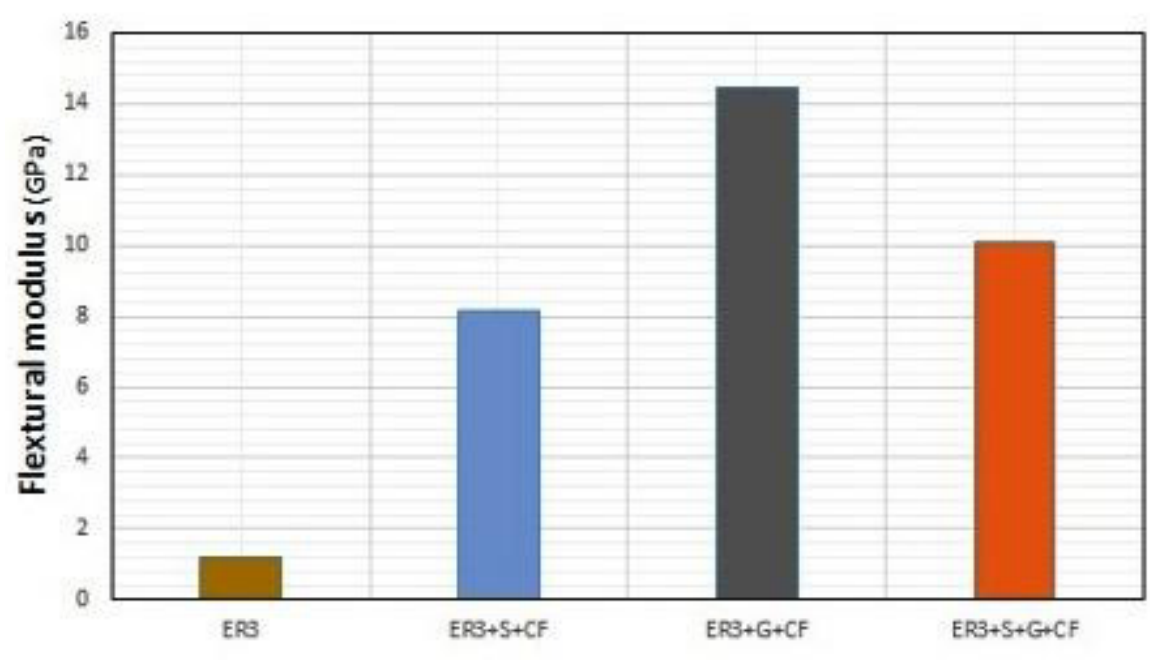

Fig.4. Flexural strength of composites

\section{IV.CONCLUSIONS}

1. Low values of mechanical properties of phenolic formaldehyde resin.

2. The mechanical properties of epoxy- phenolic formaldehyde resins are enhanced after silica and graphite reinforcement and carbon fiber reinforcement.

3. The values of mechanical properties increase with the increase of the reinforcements wt.\% additions.

\section{REFERENCES}

[1] P. Vincenzini and M. Singh, Advanced Inorganic Fibrous Composites V , Trans Tech Publications, 2006

[2] R.O. Ebewele, Polymer Science and Technology, CRC Press, New York, 2000.

[3] M. Reading, D. Elliot and V.L. Hill, A new approach to the calorimetric investigation of physical and chemical transitions, Journal of Thermal Analysis, vol.40, no.3, pp. 949-955, 1993.

[4] Jun Zheng, "Studies of pf resole / isocyanate hybrid adhesives ", Ph. D, Thesis, Virginia Polytechnic Institute and State University, 2008.

[5] ASTM, "Annual Book of ASTM Standard”, Section 8, Plastics (I). Vol. (08-01), Easton, M. V. S. A., 1989.

[6] R. J.Crawford, Plastic Engineering, $2^{\text {nd }}$ Edition, Pergamon Press USA, 1987.

[7] A.H. Hoby,“ Improvement Properties of Reinforced Plastic Materials ”, MSC Thesis , Engineering College , Babylon University , Iraq, 1999.

[8] B.A.Azhdar "Impact Fracture Toughness of Fiber Reinforced Epoxy Resin”, M.SC Thesis ,U.O.T ,1992 .

[9] A.I. Al-Mosawi, Study of Some Mechanical Properties for Polymeric Composite Material Reinforced by Fibers, Al-Qadessiyah Journal For Engineering Science, vol.2, no.1, pp.14 - 24, 2009 . 